\title{
Progress in Clinical Neurosciences: Status Epilepticus: A Critical Review of Management Options
}

\author{
Nicholas D. Lawn, Eelco F.M. Wijdicks
}

\begin{abstract}
Although generalized tonic-clonic status epilepticus (SE) is frequently seen, an evidencebased approach to management is limited by a lack of randomized clinical studies. Clinical practice, therefore, relies on a combination of expert recommendations, local hospital guidelines and dogma based on individual preference and past successes. This review explores selected and controversial aspects of SE in adults and provides a critical appraisal of currently recommended management strategies.
\end{abstract}

\begin{abstract}
RÉSUMÉ: État de mal épileptique: revue critique des options thérapeutiques. Bien que l'état de mal épileptique tonique-clonique généralisé soit observé fréquemment, l'élaboration d'une approche de traitement fondée sur des preuves scientifiques est limitée par le manque d'études cliniques randomisées. La pratique clinique est donc basée sur une combinaison de recommandations d'experts, de lignes directrices émises par l'hôpital local et de dogmes basés sur les préférences individuelles et les succès du passé. Cette revue explore des aspects sélectionnés et controversés de l'état de mal épileptique chez les adultes et fournit une évaluation critique des stratégies thérapeutiques présentement recommandées.
\end{abstract}

Can. J. Neurol. Sci. 2002; 29: 206-215

Generalized tonic-clonic status epilepticus (SE) is a not infrequently encountered neurologic emergency. Failure to adhere to a predetermined plan of action may place the patient at considerable risk of secondary brain injury. However, even with appropriate implementation of an accepted treatment plan, the outcome remains suboptimal with no evidence that current recommendations have had a measurable impact on morbidity or mortality. ${ }^{1,2}$ The aims of this review are to examine selected and controversial aspects pertaining to the diagnosis and management of SE and critically review the strategies available for refractory SE. The focus is on generalized tonic-clonic convulsive SE in adults. It is not intended to explore the complexities of the neurophysiology, neurochemistry, neuropathology or antiepileptic drug pharmacology, which are reviewed elsewhere. ${ }^{3-6}$ The data sources were predominantly obtained from a MEDLINE search for English-language articles 1966-2001, using the search term "status epilepticus". References with an emphasis on the epidemiology, electroencephalogram (EEG), treatment and outcome in generalized tonic-clonic SE in adults were selected.

\section{WHAT IS STATUS EPILEPTICUS?}

The definition of SE is evolving and debate persists as to what constitutes this entity. This has led to some heterogeneity between studies in methodology and inclusion criteria particularly with regard to seizure duration. The 1981
International League Against Epilepsy's definition of SE ("whenever a seizure persists for a sufficient length of time or is repeated frequently enough that recovery between attacks does not occur"), which has not been officially updated, remains unsatisfactory from a research viewpoint because the duration is not specified. ${ }^{7}$ However, the definition remains clinically relevant in that it describes a state where there is a failure of the normal mechanisms serving to terminate a seizure.

Definitions of SE that emphasize a specific duration appear largely to have arisen from physiologic evidence based on animal models. Meldrum and Brierley ${ }^{8,9}$ observed that in baboons neuronal dropout was seen after 25 minutes, the severity of which increased with duration of seizures. From these and other experiments, it has been concluded that prolonged seizures, even with control of associated systemic disturbances, can directly cause cerebral damage. ${ }^{10,11}$ These data have been supported to some extent in observational human studies (for review see Shorvon, $1994^{6}$ ).

From the Department of Neurology, Neurological-Neurosurgical ICU, Mayo Clinic, Rochester, Minnesota, USA(EFM); and the Department of Neurology, Royal Perth Hospital, Perth, Australia (NDL).

Received August 31, 2001. Acceptedin finalform May 6, 2002.

Reprint requests to: E.F.M. Wijdicks, Department of Neurology, W8B, 200 First Street SW, Rochester, MN 55905 USA. 
Subsequently, the Epilepsy Foundation of America working group and several major recent studies have defined SE as "any seizure lasting for 30 minutes or longer or intermittent seizures lasting for greater than 30 minutes from which the patient did not regain consciousness". 1,12,13

In the hospital-based Veterans Administration (VA) study, the entry criteria were two or more generalized convulsions without full recovery between seizures or continuous convulsive activity for more than 10 minutes. $^{2}$ The use of epilepsy-monitoring units, where it has been observed that typical tonic-clonic seizures almost invariably spontaneously cease within three minutes, has resulted in a call for a reduction in the "diagnostic threshold" for SE from 30 minutes to as low as five minutes. ${ }^{14}$ However, if a five- or 10-minute definition of SE is adopted, several potential practical issues arise. Firstly, early treatment may place patients with nonepileptic seizures or relatively prolonged but selfterminating single events at risk of overtreatment. However, there is no evidence that treatment in either of these situations results in a significant increase in serious morbidity. Secondly, this is an unrealistic duration, in most circumstances, to transport a patient with SE to the hospital, as demonstrated in an unpublished series from San Bernadino, California. ${ }^{15}$

Clearly, out-of-hospital diagnosis and management is the only way that treatment can be achieved within this time frame. A recently reported out-of-hospital study from San Francisco defined SE as "continuous or repeated seizure activity for more than five minutes without recovery of consciousness," which effectively meant that the criteria were met and treatment started if the patient was still seizing when paramedics arrived. ${ }^{16}$ In our view, at a practical level, the definition of SE should not be the topic of bedside debate and seizures should be terminated as soon as possible. From a research viewpoint, the duration of SE as defined in the San Francisco out-of-hospital study combines pragmatism and science, and we consider it reasonable to be utilized in future clinical studies.

\section{LUMPING OR SPLITTING?}

The majority of observational studies have combined a potpourri of heterogeneous conditions of diverse etiologies manifest by various forms of SE. 11,12,17,18 From epidemiological, prognostic, and management viewpoints, it is inappropriate to lump together widely disparate conditions such as myoclonic status in a comatose survivor after cardiac arrest and a brief flurry of seizures in a neurologically-normal, noncompliant epilepsy patient.

One study separated patients with "subtle" SE (coma and ictal discharges on the electroencephalogram (EEG) with or without subtle convulsive movements) from overt SE. ${ }^{2}$ As subtle SE may be seen late in the course of SE or with myoclonic SE, it was unsurprising that major differences in treatment response and prognosis were seen. Future studies should further differentiate between the various subgroups and etiologies of SE to allow for more realistic prognostication and analysis of the effect of treatment.

A classification of SE according to clinical information including pathophysiology, epilepsy syndrome, and seizure semiology combined with EEG data within various age groups (neonatal, infancy/childhood, childhood/adult, and adult) has been proposed by Shorvon ${ }^{6}$ but as yet has not been utilized in any study.

\section{Who SHOULD MANAGE STATUS EPILEPTICUS (AND THEN MIND THE STORE)?}

The reality for neurologists is that they will rarely have the opportunity to initiate management of SE. In the majority of cases, the brunt initially falls on emergency department physicians. There are no data on outcome of SE in relation to the treating physician. However, Cascino et al, ${ }^{19}$ identified that a significant proportion of patients treated for SE in a tertiary care facility were undertreated by current standards.

In most situations, the neurologist will be invited to participate in the care of these patients after an initial management program, with or without success, has been embarked upon. For each of the specialists involved, differing agendas may be present and agreed-upon. A team-based approach is paramount in providing comprehensive care including airway management, EEG interpretation, and appropriate drug therapy. It should be emphasized, however, the presenting problem is neurologic, and neurologists should be intimately involved in the patient's day-to-day care.

Although there are no data showing any improvement in outcome according to where the patient is admitted, ideally, a patient with SE should be transferred to a neurologic intensive care unit (ICU) with video-EEG monitoring capabilities.

\section{IS AN EEG REQUIRED IN EVERY CASE?}

Convulsive SE is a clinical diagnosis. However, several studies have shown that misdiagnosis of nonepileptic seizures as SE frequently occurs. ${ }^{2,20,21}$ In the VA study, where EEG was mandatory but could be performed after initiation of treatment, $20 \%$ of those initially randomized had nonepileptic seizures. ${ }^{2}$ In our view, the risks of inappropriate administration of first-line agents for SE medication are outweighed by the risks of undertreatment and the delay incurred in obtaining an EEG before treatment is generally unacceptable. An urgent EEG should be obtained in the following situations:

(i) Prolonged and severe post-ictal unresponsiveness (e.g. difficulty arousing the patient despite appropriate vigorous stimulation after a period of greater than 10 to 15 minutes) taking into consideration the effect of therapy. An EEG in this situation will differentiate coma (with no overt clinical signs of convulsive activity) due to ongoing SE from postictal somnolence.

(ii) Patients who have received neuromuscular blocking agents and sedative agents with a prolonged anesthetic effect in whom it is difficult to assess clinically for signs of ongoing seizure activity.

(iii)Patients with atypical features suggesting the possibility of pseudoseizures such as alternating or out of phase limb movements, prominent pelvic thrusting, side-to-side head movements and forced eye closure.

(iv)Refractory status epilepticus, where seizures persist despite treatment with appropriate doses of benzodiazepines and phenytoin.

After initial treatment, ongoing EEG monitoring may allow identification and treatment of clinically-unrecognized seizures. Although there is indirect evidence this may improve outcome, this need not be routine and can be tailored to patients in whom the above criteria are met. ${ }^{22,23}$ Where possible, digital video-EEG 
monitoring should be used as it allows for improved clinical correlation and EEG analysis.

\section{EEG INTERPRETATION IN STATUS EPILEPTICUS: TREATABLE SPIKES OR DAMAGED CORTEX?}

Electroencephalographic analysis during and after seizures is difficult and skilled interpretation is necessary. This includes differentiation of movement artefact from electrographic seizure discharges and recognition of the varying ictal and post-ictal patterns and the evolution of EEG abnormalities with ongoing SE. ${ }^{24,25}$ One of the controversial patterns seen is periodic epileptiform discharges (PEDs). Although a strict definition of PEDs does not exist, these usually occur at a rate of less than $3 \mathrm{~Hz}$ and should not show any significant spatio-temporal evolution. They may be lateralized (PLEDs), bilaterally independent (BiPLEDs), bilaterally synchronous/generalized (GPEDs), or multifocal independent. ${ }^{26}$

Unless there is a clinical correlate such as subtle face or limb twitching or nystagmoid eye movements, PLEDs and BiPLEDs are generally considered an interictal phenomenon reflecting an acute disturbance of cerebral function often related to an underlying structural abnormality. ${ }^{26}$ Periodic lateralized epileptiform discharges are often transiently seen following uncomplicated tonic-clonic seizures in epilepsy patients undergoing routine diagnostic video-EEG monitoring, but GPEDs are rarely encountered. However, the pattern of GPEDs, at times with varying voltage asymmetry over either hemisphere, has been repeatedly demonstrated in animal studies and patients with prolonged SE. ${ }^{22-25,27,28}$ In the comatose patient without any subtle motor manifestations but with previously recognized clinical seizures, this pattern should be regarded as ictal. Difficulties arise when GPEDs are seen in the same situation but without any preceding clinical ictus. If no alternative cause can be determined, it is reasonable to also consider this ictal. Therefore, the interpretation and treatment of any periodic epileptiform discharges seen in the context of SE should be based on the clinical situation, knowledge of the history and examination findings, the results of neuroimaging, and careful EEG assessment. The presence of PEDs in SE may have some prognostic significance. Studies have variably suggested that the outcome is worse in patients with PEDs although the data do not appear to have been corrected for age and type of SE. ${ }^{22,23,25,27}$

Burst suppression may be seen as a direct consequence of SE and its cause or related to treatment. This is also not usually considered an electrographic seizure pattern unless myoclonic jerks or some other clinical accompaniment are seen in association with the bursts or rhythmic epileptiform activity is seen during periods of suppression. ${ }^{24}$

The presence of burst suppression in association with postanoxic-ischemic myoclonus signifies an ominous prognosis but the prognosis of this EEG finding in otherwise uncomplicated SE is not known. ${ }^{23,30}$ Lastly, the attainment of certain EEG patterns have been advocated as a "therapeutic endpoint". 31,32 If the seizures are controlled clinically and there is no EEG evidence of ongoing seizure activity, any EEG pattern is acceptable. Although frequently necessary in refractory SE, titration of anesthetic agents to an iso-electric or burst-suppression pattern is at present not known to be of any benefit and may, in fact, be harmful due to the cardio-depressant effects. ${ }^{33,34}$ The reality is, however, that in most institutions, neurologists or EEG-trained personnel will not be continually observing minute-to-minute changes during EEG monitoring. Therefore, attainment of clinical seizure control and an associated easily-recognized EEG pattern compatible with this, such as burst suppression, may simplify EEG assessment and facilitate communication with the neurology team if changes occur.

\section{MORBIDITYAND MORTALITY - CAUSE OR CONSEQUENCE?}

Mortality in large series varies between 15 and $30 \% .^{12,13,17,18,35,36}$ Etiology has been repeatedly demonstrated to be the major determinant of mortality in SE. ${ }^{17,18,35,36}$ However, where attempts have been made to identify the mortality rate directly due to SE, this falls dramatically to $0-3 \% .^{17,37}$ Age is clearly a factor; but when corrected for etiology, it becomes less significant. ${ }^{35,36}$ Duration of SE has generally been shown to be predictive of mortality independent of etiology although assessment of this in retrospective or even prospective studies is difficult. ${ }^{17,18,35,36}$ A recent study demonstrated that patients with prolonged seizure episodes lasting 10 to 29 minutes had a more favorable outcome than those with SE defined by the Epilepsy Foundation of America criteria, i.e. greater than 30 minutes. ${ }^{38}$ In addition, SE in adults presenting with intermittent seizures may have a more favorable prognosis than continuous SE. ${ }^{39}$

Morbidity due to SE has rarely been assessed; and, while also clearly linked to etiology, detailed analysis of this in a modern, prospective series may be enlightening. ${ }^{17,40}$ Epilepsy frequently follows SE but, whether this is due to the seizures themselves or related to the underlying cause, is unclear. Hauser ${ }^{41}$ found that acute symptomatic SE (i.e. with an identifiable cause) was associated with a three-fold increased risk of development of epilepsy compared to less prolonged acute symptomatic seizures. Status epilepticus, as the first seizure in the context of a remote symptomatic etiology (i.e. related to a previous neurologic insult), was also associated with a higher risk of further unprovoked seizures. ${ }^{42}$ However, this relationship does not appear to hold for unprovoked SE. ${ }^{43}$ With regard to treatmentassociated morbidity, no significant differences in hypoventilation, hypotension requiring treatment or dysrhythmias were identified among the four treatments utilized in the VA study. ${ }^{2}$ Similarly in the San Francisco out-of-hospital study, the above complications and ICU admission were more frequent in placebo-treated patients than those who received benzodiazepine treatment. ${ }^{16}$

\section{A P Ractical Guide to Management}

\section{General measures}

Management of SE should begin in the field or during transportation to hospital. Despite the proven efficacy and safety, we suspect that out-of-hospital treatment options remain underutilized. ${ }^{16,44,45}$ Once in hospital, SE treatment should be focused on management of acute complications, termination of seizures, prevention of recurrence, and investigation and treatment of potential precipitating causes.

The first priority is airway control and avoidance of hypoxia. Deciding whether and when to intubate remains a clinical 
decision made in conjunction with emergency or intensive care physicians based on the patient's ability to maintain respiratory drive, protect the airway, and preserve adequate lung function.

Assessment of the etiology of the SE should occur coincident with the initial management. The most frequent cause of SE in large adult series is an acute process involving the central nervous system (CNS), most commonly stroke, hypoxia/ ischemic encephalopathy, infection, metabolic, drug overdose, trauma, and alcohol-related. ${ }^{12,13,17,18}$ Status epilepticus occurring in patients with remote CNS insults, including patients with symptomatic epilepsy with low antiepileptic drug levels, comprise the majority of the remainder.

Emergency investigations are, to a large extent, dictated by the history and examination. However, as a minimum, electrolytes including calcium and magnesium, glucose, complete blood count, liver and renal function should be urgently performed. Antiepileptic drug levels should be assessed as appropriate but often it is not known what the patient is taking. It is, therefore, helpful to take extra blood samples for analysis once the history can be clarified. In addition, a drug screen should be performed although this will rarely be available on an urgent basis. Subsequent investigations, including CT head and $\mathrm{CSF}$, are frequently necessary but these may be delayed until seizures are controlled.

\section{Termination of seizures}

The second priority, once the airway is controlled, oxygen delivery is secured, and adequate blood pressure maintained, is management of the seizures. The principal goal is to eliminate clinical and electrical seizure activity as quickly as possible. The earlier seizures are controlled, the easier they are to treat. ${ }^{36,46}$ Earlier seizure control ensures that subsequent, more hazardous, measures that may adversely affect outcome will not be necessary. Although no controlled trial of in-hospital treatment of SE exists, several randomized trials provide guidance, at least for initial treatment, and provide the basis against which future drug combinations could be tested. ${ }^{2,47,48}$

\section{(a) First-line agents - best shot at success}

The first-line drug of choice is intravenous lorazepam (LZP). Although direct comparison with diazepam (DZP) did not show any advantage in efficacy, other studies have suggested that LZP may be associated with a reduced rate of seizure recurrence. ${ }^{16,48,49}$ In the San Francisco out-of-hospital study, the response rates (i.e. cessation of seizures) were placebo $21 \%$, DZP $43 \%$ and LZP 59\%. ${ }^{16}$ In the VA study, the rate of seizure recurrence with LZP alone was no different to that of DZP and phenytoin (PHT) also suggesting the possibility of a more extended duration of action. ${ }^{2}$ Other potential advantages of LZP include its rapid clinical onset and possibly lower levels of respiratory or cardiac depression. ${ }^{49-51}$ Although the VA trial involved administration of LZP dose of $0.1 \mathrm{mg} / \mathrm{kg}$ in adults, we feel it is reasonable to use an initial dose of $4 \mathrm{mg}$. ${ }^{2,48}$ If LZP is unavailable, DZPis an established alternative. The dose given in the VA trial was $0.15 \mathrm{mg} / \mathrm{kg}$, and it is therefore appropriate to start with an initial dose of $10 \mathrm{mg}$ as in the study by Leppik. ${ }^{2,48}$ Despite a longer half-life, DZPappears to have a shorter duration of anti-epileptic effect related to more extensive tissue distribution of the unbound drug. ${ }^{51}$ With either drug, 50 to $70 \%$ of seizures will cease. ${ }^{2,16,48}$ The decision when to repeat a dose of benzodiazepines is arbitrary; but, in general, if there is no response within two to three minutes, a further dose should be given. Intravenous clonazepam has been widely used in Europe and elsewhere but is not available in North America. It is said to have a longer duration of action than DZP and lower propensity for the development of acute tolerance than LZP. A direct comparison with LZPin SE did not show any clear differences. ${ }^{52}$

Accomplishment of intravenous access is often difficult and intramuscular or alternative routes of administration of first-line anticonvulsants may be necessary. Rectal DZP may be given although the practical difficulties of administering this to seizing adults may be underestimated. Both LZPand DZP can be given intramuscularly but peak levels are variable, typically lower, and delayed. ${ }^{53,54}$ Intramuscular midazolam has recently been shown to be effective and safe and may be preferable to either LZP or DZP. ${ }^{55}$ Of the other first-line agents, PHTcannot be given by the intramuscular route. Intramuscular fosphenytoin (fosPHT) (see below) can be used safely although its role in SE has not been studied. It is rapidly and completely absorbed after injection into muscle and is quickly converted to produce therapeutic PHT plasma concentrations within 30 minutes of administration. ${ }^{56}$ Phenobarbitone (PB) can also be safely given this way but peak levels do not occur early enough for this to be recommended.

Intravenous loading with PHT after initial treatment with benzodiazepines has become established clinical practice. This emerged following the recognition that the delay in achieving peak cerebral PHT levels necessitated by its slow infusion rate meant that PHT alone was unsatisfactory for acute management of seizures. ${ }^{57}$ This was supported by the findings in the VAstudy where it was demonstrated that PHT alone was significantly less effective than LZP alone. ${ }^{2}$

Phenytoin should be administered immediately after LZP if seizures persist. The loading dose of PHT $(20 \mathrm{mg} / \mathrm{kg})$ should be infused in at least $100 \mathrm{ml}$ of $0.9 \%$ normal saline at a rate no greater than $50 \mathrm{mg} / \mathrm{minute}$. An average dose will, therefore, take approximately 30 minutes to administer. If there are continued seizures, a further $5-10 \mathrm{mg} / \mathrm{kg}$ of PHT should be given, and preparation for administration of a second-line agent should commence. The recommendation for further PHT has become a standard part of treatment algorithms in multiple reviews of SE. 1,3,4,46 The scientific basis for this is unclear. However, the authors and others have recognized that serum PHT levels shortly after a loading dose of $20 \mathrm{mg} / \mathrm{kg}$ are often "subtherapeutic" or in the low-therapeutic range and the risks of transient PHT toxicity and the time taken to give a further dose appear to be justified. ${ }^{58}$

Fosphenytoin, a water-soluble prodrug of PHT, is likely to replace PHT although concerns regarding cost have limited its widespread use. However, fosPHT is safer and likely to be similarly effective. Fosphenytoin may be given at 100 to 150 phenytoin-equivalent units per minute. Although the rapid infusion of fosPHT may achieve free PHT levels sooner than PHT, there is no evidence that this results in faster control of seizures. Moreover, there is some evidence from animal models that initial brain PHT levels may be lower with fosPHT. ${ }^{59,60}$ The potential problems with intravenous PHTrelate to the addition of sodium hydroxide and propylene glycol to enable a soluble intravenous compatible form. These additives and the very high $\mathrm{pH}$ of intravenous PHT contribute to hypotension, cardiac 
dysrhythmias and, if there is extravasation, thrombophlebitis "purple glove syndrome" (PGS), adverse effects seen more commonly in comatose patients, the elderly and in those who are poorly hydrated. ${ }^{61-63}$ Purple glove syndrome refers to the development of progressive edema, discoloration, and pain locally in a limb following the infusion of PHT ${ }^{61}$ While fosPHT has not been associated with PGS, it should not be assumed to be free of any cardiac adverse effects and ECG, and blood pressure monitoring are necessary during infusion.

In the patient with SE who has been taking PHT, the question arises as to whether the dose should be modified, given that the level is unlikely to be available in the majority of cases. In our opinion, the initial loading dose of $20 \mathrm{mg} / \mathrm{kg}$ should be given, acknowledging the risk of transient toxicity (if a level arrives during the infusion the dose can be modified). In patients with known PHT allergy or significant pre-existing cardiac arrhythmias, such as heart block, PHTshould be avoided and the agents below, in particular PB, should be considered. If there is a history of carbamazepine or PB allergy and no known history of PHT use, we feel the risk of "cross-reaction" to PHT is low enough to warrant its use. Conversely, if there is a known history of severe anticonvulsant-hypersensitivity syndrome to $\mathrm{PB}$ or carbamazepine, the risk of a cross-reaction is great enough to warrant avoiding PHT, and alternatives including continuous infusion of benzodiazepines should be considered. ${ }^{64}$

The modern role of PB in the initial management of SE is unclear. Despite a wealth of clinical experience suggesting effectiveness of $\mathrm{PB}$, there are sparse evidence-based data supporting its use. Two controlled trials have shown that it is effective as a first-line agent. ${ }^{2,47}$ In the VA trial, a dose of $15 \mathrm{mg} / \mathrm{kg}$ was given at a rate of up to $100 \mathrm{mg} / \mathrm{minute}$ and was found to be as efficacious as LZPalone or DZPand PHT. ${ }^{2}$ In the study of Shaner et $\mathrm{al},{ }^{47} \mathrm{~PB}$ was associated with a shorter response latency and shorter duration of SE than combination DZP and PHT. The safety profile was comparable between both groups. However, the results of this study are difficult to interpret due to a complicated protocol and drug doses that would not be considered optimal with the present level of knowledge. The major disadvantage of $\mathrm{PB}$, particularly when combined with benzodiazepines, is respiratory depression resulting in intubation, although this may be overestimated. ${ }^{57}$ When used alone, as in the VA trial, there was no greater rate of hypoventilation associated with $\mathrm{PB}$ as compared to the other treatment options. ${ }^{2}$ Although PB appears to be a more than viable alternative in the initial management of SE at present, we reserve its use for those with a contraindication to PHT.

Intravenous valproate or divalproex sodium ("Depacon") has recently become available. Despite evidence of effectiveness in animal models, there are, as yet, limited data on its efficacy in human SE. ${ }^{65,66}$ It may also be a viable alternative for patients to whom PHT cannot be given. Intravenous valproate can be infused rapidly at up to $6 \mathrm{mg} / \mathrm{kg} / \mathrm{minute}$ in stable epilepsy patients and patients in ICU for a variety of conditions without adverse cardiopulmonary effects. ${ }^{67,68}$ The dose is not yet established. Animal data suggest that hypertherapeutic levels may be required but published data in humans, the majority of which are based on stable non-SE patients with epilepsy, have used doses between 20 and $40 \mathrm{mg} / \mathrm{kg}$ achieving, in one study, mean post-infusion serum levels of 133 micrograms per milliliter. ${ }^{65,67}$ Recently, a series of pediatric patients with refractory SE treated with intravenous intravenous valproate was reported. ${ }^{69}$ The protocol involved a loading dose of $20-40 \mathrm{mg} / \mathrm{kg}$ over one to five minutes, repeating this if necessary and then an infusion of $5 \mathrm{mg} / \mathrm{kg} /$ hour continuing until seizure free. Intravenous valproate appeared to be safe and highly effective for various sub-types of SE, including generalized tonic-clonic SE. Whether this data can be extrapolated to adults remains unclear.

Intravenous magnesium has a role in eclampsia-related seizures with a randomized controlled study showing a clear advantage compared to PHT or DZP. ${ }^{70}$ At present, there is no evidence for any role of magnesium in noneclamptic seizures unless low magnesium is identified as a potential etiology. ${ }^{71,72}$

\section{(b) Second-line agents - trouble ahead}

The clinician suddenly facing a patient not responding to initial treatment of $\mathrm{SE}$ is in a difficult situation. If seizures remain uncontrolled or recur following at least two doses of benzodiazepines to a total of $0.1 \mathrm{mg} / \mathrm{kg}$ of LZPor $30 \mathrm{mg}$ DZPand intravenous PHTor fosPHTloading to a total of $30 \mathrm{mg} / \mathrm{kg}$ second line, agents should be used. Typically, by this stage, the patient will have been in established SE for over 20 minutes; and, although definitions in the literature vary, we consider it is reasonable to consider this refractory status epilepticus. At this stage, the clinical manifestations have often evolved from overt tonic-clonic seizures to "subtle" or nonconvulsive SE where there may be minimal motor activity with intermittent low amplitude clonic movements often more limited in distribution. ${ }^{6}$ Preparation for the use of other agents and the possibility of intubation and mechanical ventilation should by this time be underway. In addition, arrangements for an EEG and/or continuous EEG monitoring should be initiated. At this point, a reassessment of the patient and the reasons for failure of initial therapy is warranted. Assuming that the dose of the above drugs was sufficient and the patient does not have pseudoseizures, metabolic parameters should be re-examined and the underlying etiology reconsidered.

Without disseminating undue pessimism, the outlook for successful treatment of refractory SE after failure of initial agents is dismal. No data based on clinical trials are available to guide therapy and treatment is, therefore, empiric and based on a combination of personal experience and anecdote. The VA trial showed that when treating overt SE first-line treatment success rates were LZP64.9\%; phenobarbital 58.2\%; DZP/ PHT 55.8\%, and PHT alone $43.6 \%$. The aggregate response rate to secondline agents for patients who did not respond to first-line agents was $7.0 \%$, and it was $2.3 \%$ for third-line agents. ${ }^{59}$ However, the second and third line agents were predetermined by the study protocol with $\mathrm{PB}$ used rather than any of the newer agents in three of the four options. ${ }^{2}$ Intravenous PB has traditionally been utilized as a second line agent after failure of benzodiazepines and PHT. ${ }^{1,4}$ This practice has never been supported by an appropriately designed clinical trial, but a recent survey confirmed that most epilepsy experts continue to advocate the use of PB in this situation. ${ }^{73}$ In our opinion, the second-line drug, after failure of initial therapy with LZP and PHT or fosPHT, should be midazolam. There is limited evidence for the efficacy or safety of midazolam in this situation. However, the rationale 


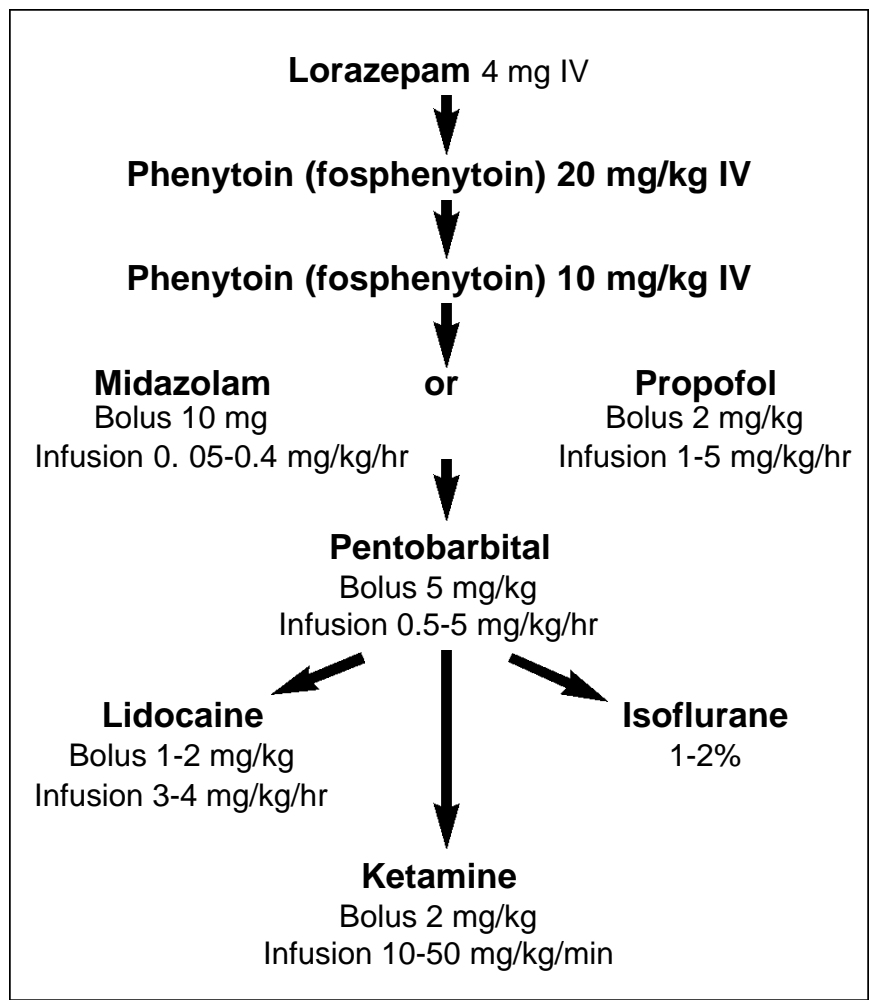

Figure: Flow diagram showing pharmaceutical options to treat status epilepticus.

for this approach is that, if the initial therapy is given in a timely fashion and in appropriate doses, control of SE as defined in recent trials will be achieved in the majority of patients. ${ }^{2,16}$ Where initial agents fail there is a low likelihood of success with PB as shown in the VAstudy. In addition, PB cannot be rapidly infused, thus incurring further delays. Those who remain in SE should be defined as refractory at this point rather than at an arbitrary time after seizure onset. This redefinition of the conceptual framework of SE justifies the earlier use of secondline agents.

Midazolam in doses necessary to control refractory SE, particularly after initial therapy with benzodiazepines and, in some cases, failure of barbiturates, is likely to result in intubation becoming necessary. In addition, as clinical seizures may be difficult to assess in this setting, these patients should undergo continuous EEG monitoring to confirm electrographic cessation of seizures. Midazolam causes various EEG changes, most commonly drug-induced fast activity and generalized slowing and it is likely that seizure control will occur before a burst suppression pattern is seen. ${ }^{74,75}$ The recommended loading dose of midazolam is $10 \mathrm{mg}$ up to $0.2 \mathrm{mg} / \mathrm{kg}$ followed by an infusion at a rate 0.05 to $0.4 \mathrm{mg} / \mathrm{kg} /$ hour although higher doses may be necessary. ${ }^{76-78}$ We have found midazolam to be well-tolerated although we have encountered significant hypotension at higher doses, frequently requiring inotropic support with dopamine. ${ }^{78,79}$ In our experience, longer-term use of this drug is limited by tachyphylaxis, and typically its effectiveness declines after 24 to 48 hours. In a recent series of 33 episodes of refractory SE treated with midazolam, immediate seizure control was achieved in $82 \%$, but breakthrough seizures (which were generally electrographic, without any clinical accompaniment) occurred in $56 \%$, emphasizing the importance of aggressive coadministration of definitive anti-epileptic drug treatment. ${ }^{79}$

An alternative to midazolam is propofol, but experience with this agent in SE is also relatively limited. Propofol is a nonbarbiturate, anesthetic agent with clear anticonvulsant properties, although the exact mechanism of action is unknown. ${ }^{80}$ Several small, open, uncontrolled studies have described the outcome of propofol use in refractory SE, often without EEG monitoring. ${ }^{80-82}$ Most of these clinical reports discuss the use of propofol after traditional treatment regimens, including barbiturates, have failed or are not tolerated. In one study of refractory SE, there was a slightly lower rate of seizure control with propofol $(63 \%)$ compared to pentobarbital (82\%), but seizure control was achieved more quickly in the propofol-treated patients. ${ }^{81}$ The usual dose of propofol is a $2 \mathrm{mg} / \mathrm{kg}$ bolus followed by an infusion dose of $1-5 \mathrm{mg} / \mathrm{kg} /$ hour depending on the clinical response. Advantages of propofol, compared with traditional barbiturate anesthetic agents, include better cardiovascular tolerability and a more favorable pharmacokinetic profile, allowing for rapid assessment of efficacy and neurologic assessment upon drug withdrawal. Propofol has been associated with a variety of abnormal movements, including opisthotonos, myoclonus, and choreoathetoid movements. ${ }^{83-86}$ However, there is no evidence that propofol causes seizures, and the various neuro-excitatory events reported appear to occur at lower doses or at induction and are not seen at the doses used for SE ${ }^{87}$ Of greater concern is the, as yet unexplained, "propofol-infusion syndrome" involving metabolic acidosis, renal failure, and cardiovascular collapse associated with prolonged use of propofol at the type of doses likely to be necessary in SE. ${ }^{88}$ Whether this was the basis for the minor excess in mortality in the small case series described above is unclear but, with the information currently available, we do not think propofol should be the first drug employed in refractory SE. ${ }^{81,82}$

Drug levels can be performed for both midazolam and propofol but do not contribute to management and dose should be titrated to clinical and EEG response and patient tolerability. Once seizures are controlled either agent should be tapered and stopped over 24 to 48 hours. $^{81}$

\section{(c) Third-line agents for seizure termination - last resort}

If there is no response to high dose benzodiazepine infusion, the next step should involve an anesthetic barbiturate of which the best information and widest experience is available for pentobarbitone and thiopentone. Some authors have advocated the use of very high dose PB on the basis that this may have a more selective antiepileptic action and is safer. ${ }^{89}$ However, this evidence was based on a case series in children, and the adverse effect profile at the doses suggested are probably no less welltolerated than with pentobarbital or thiopentone. In addition, PB has a longer latency to anesthetic effect, a longer duration of action, and is eliminated more slowly. ${ }^{6}$ Barbiturate anesthetics clearly have anticonvulsant action. While there is theoretical evidence for a neuroprotective effect with barbiturates, there is 
no evidence that this leads to any measurable difference in the outcome of SE. These drugs should only be used in ICU with the assistance of personnel experienced in their use. Invasive hemodynamic monitoring is often necessary and continuous EEG recording to monitor seizure activity is mandatory.

Pentobarbital has been traditionally advocated in North America as a third-line agent in refractory SE and guidelines have been established for its use. ${ }^{1,58,90}$ The loading dose used in studies ranged between 5 and $20 \mathrm{mg} / \mathrm{kg} .{ }^{1,6,58,90-92}$ We suggest an initial dose of $5 \mathrm{mg} / \mathrm{kg}$, increased as necessary to teminate clinical and electrographic seizure activity. This should be followed by an infusion rate of 0.5 to $5 \mathrm{mg} / \mathrm{kg} / \mathrm{hour}$ although in one study seizures invariably recurred following an initial response to a bolus, at dose rates of less than $2.5 \mathrm{mg} / \mathrm{kg} / \mathrm{hour} .^{58} \mathrm{In}$ the majority of case series reported, seizures were rapidly controlled with pentobarbital. Hypotension is to be expected but can be usually controlled with vasopressors. Thiopentone, a "parent drug" of pentobarbital, has a similar profile to its metabolite although the elimination half-life is more prolonged with the possible advantage of reducing the rate of seizurerecurrence on drug withdrawal. ${ }^{6}$ The suggested dose is a bolus of 100 to $250 \mathrm{mg}$ with further $50 \mathrm{mg}$ boluses until seizures are controlled, followed by an infusion of $3-5 \mathrm{mg} / \mathrm{kg} / \mathrm{hour}{ }^{6,93}$ Cardiovascular intolerability is also frequently seen. ${ }^{6,94}$ Both drugs are reported to predispose to infection related to adverse effects on immune function, which may compromise the care of a patient already at serious risk of ventilator-associated pneumonia and other infectious complications. ${ }^{95}$ During infusion, serum barbiturate levels can be monitored although therapeutic endpoints should be based primarily on clinical and electrographic response. There are little data regarding the appropriate method of weaning the barbiturate anesthetics. Serum drug levels have been advocated to guide the rate of withdrawal but a practical approach with pentobarbital is to begin weaning 12 to 24 hours after the last clinical or electrographic seizure and taper the dose by 0.5 to $1.0 \mathrm{mg} / \mathrm{kg} /$ hour every four to six hours. ${ }^{58,90,96}$ If there is recurrence of SE, the infusion should be reinstated and continued again at a level to suppress clinical and electrographic seizures for at least 24 hours prior to another trial of drug withdrawal. Other antiepileptic drugs should be continued during barbiturate coma utilizing serum drug levels to optimize dose.

The majority of contemporary reviews of SE do not provide any details of options available in the not-infrequent situation where high-dose barbiturates fail. Barbiturate failure may be due to hemodynamic intolerance, recurrent seizures on attempted withdrawal, or failure of the drug itself. Inhalational anesthetics may be considered under these circumstances. Experience with halothane, enflurane, and isoflurane has been reported. The administration of these volatile agents involves significant logistical difficulties. Full-time input from an anesthesiologist and appropriate facilities in the ICU are required. Although halothane has been previously advocated, this should be avoided because of the adverse cardiac effects and the risk of hepatotoxicity. ${ }^{97,98}$ Isoflurane has well-characterized anticonvulsant properties in animal studies. In humans, it appears to provide anticonvulsant action at levels low enough to be welltolerated but experience in refractory SE is limited to a few case reports. $^{99-105}$ In a multi-center series of nine patients with 11 episodes of refractory SE, isoflurane stopped or substantially attenuated EEG and convulsive activity in all cases. ${ }^{104}$ All patients developed significant hypotension requiring fluids and/or vasopressors. The necessary end-tidal isoflurane concentrations ranged between 0.8 and $3.0 \%$, titrated to burst suppression (rather than electrical silence as the latter was deemed too dangerous given the doses necessary to achieve this), administered for between one and 55 hours. However, nine of 11 recurred with withdrawal of isoflurane. This led the authors to surmise that the role of this agent and other inhalational anesthetics was to provide temporary seizure control while other antiepileptic agents work and the underlying neurologic condition was treated. There are no data on the newer inhalational agents such as sevoflurane or desflurane, although there is some evidence that the former of these may, in fact, be epileptogenic. ${ }^{106,107}$

Lastly, there are multiple case reports of successful treatment of SE with lidocaine. ${ }^{6,108}$ Although implicated as a potential cause of seizures, low-dose lidocaine appears to have anticonvulsant properties. ${ }^{109}$ In adults, it can be given as a bolus of 1 to $2 \mathrm{mg} / \mathrm{kg}$ occasionally followed by an infusion at 2 to $3 \mathrm{mg} / \mathrm{kg} /$ hour. ${ }^{6,110}$ The role of lidocaine in SE and refractory SE is unclear. Some authors have advocated its early use in situations where drugs that cause respiratory depression cannot be used or as temporary measure while preparations for more definitive therapies are undertaken. ${ }^{110}$ There has also been considerable interest in the use of ketamine. ${ }^{111}$ This short-acting NMDA receptor antagonist does not cause respiratory depression and has outdone antiepileptic drugs in anecdotal cases.

\section{Prevention of recurrence}

Although the priority in the acute management of SE is rapid control of seizures, strategies to prevent seizure recurrence should be initiated. The selection of appropriate oral antiepileptic drugs and longer-term issues regarding duration of treatment and rationalization of often complicated polydrug regimens depends on the clinical situation and should be individualized to each patient and to the electroclinical syndrome.

\section{OVERVIEW}

We came away with the unsatisfactory realization that the number of randomized studies of SE is inversely proportional to the number of review articles (to which we added one!). However, recent clinical advances include the following:

1) Epidemiological data demonstrating etiology of SE in the modern era, identifying risk factors for a poor outcome, and promoting a redefinition of SE focused on early identification and treatment.

2) Two major randomized studies have been completed; one, out-of-hospital, indicating that rapid, safe and effective treatment of SE can be achieved in the community. The other also confirms the effectiveness of early in-hospital treatment with benzodiazepines while importantly reminding us of the poor outlook if initial treatment fails.

3) Information regarding the role of EEG in SE, including the spectrum of EEG abnormalities, their relationship to treatment and prognosis, confirming that EEG monitoring is mandatory for refractory SE and that a minimal EEG-guided 
target in the therapy of SE should be the elimination of unequivocal electrographic seizure activity.

However, future epidemiological analysis needs to be refined so that the inextricable links between etiology, seizure type, and outcome can be delineated from the relationship between treatment and outcome, allowing treatment to be individualized for the clinical situation. Out-of-hospital treatment strategies need to become widespread to have any impact on mortality and morbidity of SE. Once in hospital, a number of major treatment issues remain unresolved: the optimal sequence of currently available anti-epileptic drugs in SE, development of a drug that can be safely administered and achieve peak brain levels more rapidly than PHT, the appropriate use of the second-line agents, and the role of N-methyl-D-aspartate receptor antagonists and agents with neuro-protective properties.

\section{REFERENCES}

1. Working Group on Status Epilepticus. Treatment of convulsive status epilepticus. Recommendations of the Epilepsy Foundation of America's working group on status epilepticus. JAMA 1993;270:854-859.

2. Treiman DM, Meyers PD, Walton NY, et al. A comparison of four treatments for generalized convulsive status epilepticus. N Engl J Med 1998;339:792-798.

3. Gillam FG. Status epilepticus. In: Wylie E (Ed). The treatment of epilepsy: principles and practice (2nd ed.). Baltimore: Williams and Wilkins, 1997:666-676.

4. Treiman DM. Treatment of status epilepticus. In: Engel J and Pedley TA (Eds). Epilepsy: A comprehensive textbook. Philadelphia: Lippincott-Raven, 1997:1317-1323.

5. Eadie MJ, Tyrer, JH. Anticonvulsant therapy, pharmacological basis and practice. (3rd ed.). New York: Churchill Livingstone, 1989.

6. Shorvon S. Status epilepticus: its clinical features and treatment in children and adults. Cambridge, England: Cambridge University Press, 1994.

7. Proposal for revised clinical and electroencephalographic classification of epileptic seizures: from the Commission on Classification and Terminology of the International League against Epilepsy. Epilepsia 1981;22:489-501.

8. Meldrum B, Brierly JB. Prolonged epileptic seizures in primates: ischemic cell change and its relation to ictal physiological events. Arch Neurol 1978;28:10-17.

9. Meldrum BS, Vigouroux RA, Brierly JB. Systemic factors and epileptic brain damage: prolonged seizures in paralyzed, artificially ventilated baboons. Arch Neurol 1973;29;82-87.

10. Wasterlain CG. Mortality and morbidity from serial seizures; an experimental study. Epilepsia 1974;15:155-176.

11. Nevander G, Ingvar M, Auer R, Siesjo BK. Status epilepticus in well-oxygenated rats causes neuronal necrosis. Ann Neurol 1985;18:281-290.

12. DeLorenzo RJ, Hauser WA, Towne AR, et al. A prospective, population-based epidemiologic study of status epilepticus in Richmond, Virginia. Neurology 1996;46:1029-1035.

13. Hesdorffer DC, Logroscino G, Cascino G, Annegers JF, Hauser WA. Incidence of status epilepticus in Rochester, Minnesota, 19651984. Neurology 1998;50:735-741.

14. Lowenstein DH, Bleck T, Macdonald RL. It's time to revise the definition of status epilepticus. Epilepsia 1999;40:120-122.

15. Jordan KG. Status epilepticus. A perspective from the neuroscience intensive care unit. Neurosurg Clin N Am 1994;5:671-686.

16. Alldredge BK, Gelb AM, Isaacs SM, et al. A comparison of lorazepam, diazepam, and placebo for the treatment of out-ofhospital status epilepticus. N Engl J Med 2001;345: 631-637.

17. Aminoff MJ, Simon RP. Status epilepticus: causes, clinical features and consequences in 98 patients. Am J Med 1980;69:657-666.

18. Oxbury JM, Whitty CWM. Causes and consequences of status epilepticus in adults: a study of 86 cases. Brain 1971;94:733-744.

19. Cascino G, Hesdorffer DC, Logroscino G, Hauser WA. Treatment of nonfebrile status epilepticus in Rochester, Minn, from 1965 through 1984. Mayo Clin Proc 2001;76:39-44.

20. Howell SJ, Owen L, Chadwick DW. Pseudostatus epilepticus. Q J Med 1989;71:507-519.

21. Walker MC, Howard RS, Smith SJ, et al. Diagnosis and treatment of status epilepticus on a neurological intensive care unit. Q J Med 1996;89: 913-920.

22. DeLorenzo RJ, Waterhouse EJ, Towne AR, et al. Persistent nonconvulsive status epilepticus after the control of convulsive status epilepticus. Epilepsia 1998;39:833-840.

23. Jaitly R, Sgro JA, Towne AR, Ko D, DeLorenzo RJ. Prognostic value of EEG monitoring after status epilepticus: a prospective adult study. J Clin Neurophysiol 1997;14:326-334.

24. Treiman DM. Electroclinical features of status epilepticus. J Clin Neurophysiol 1995;12:343-362.

25. Garzon E, Fernandes RMF, Sakamoto AC. Serial EEG during human status epilepticus: evidence for PLEDs as an ictal pattern. Neurology 2001;57:1175-1183.

26. Pohlmann-Eden B, Hoch DB, Cochius JI, Chiappa KH. Periodic lateralized epileptiform discharges - a critical review. J Clin Neurophysiol 1996;13:519-530.

27. Nei M, Lee JM, Shanker VL, Sperling MR. The EEG and prognosis in status epilepticus. Epilepsia 1999;40:157-163.

28. Meldrum BS, Horton RW. Physiology of status epilepticus in primates. Arch Neurol 1973;28:1-9.

29. Lothman EW, Bertram EH, Bekenstein JW, Perlin JB. Selfsustaining limbic status epilepticus induced by 'continuous' hippocampal stimulation: electrographic and behavioral characteristics. Epilepsy Res 1989;3:107-119.

30. Young GB, Gilbert JJ, Zochodne DW. The significance of myoclonic status epilepticus in postanoxic coma. Neurology 1990;40:1843-1848.

31. Van Ness PC. Pentobarbital and EEG burst suppression in treatment of status epilepticus refractory to benzodiazepines and phenytoin. Epilepsia 1990;31:61-67.

32. DeGiorgio CM. Burst-suppression patterns in status epilepticus. The burst-suppression duration ratio: a marker of the end of clinical status epilepticus. J Epilepsy 1993;6:32-35.

33. Krishnamurthy KB, Drislane FW. Depth of EEG suppression and outcome in barbiturate anesthetic treatment for refractory status epilepticus. Epilepsia 1999;40:759-762.

34. Jantti V, Eriksson K, Hartikainen K, Baer GA. Epileptic EEG discharges during burst suppression. Neuropediatrics 1994;25: 271-273.

35. Logroscino G, Hesdorffer DC, Cascino G, Annegers JF, Hauser WA. Short-term mortality after a first episode of status epilepticus. Epilepsia 1997;38:1344-1349.

36. Towne AR, Pellock JM, Ko D, DeLorenzo RJ. Determinants of mortality in status epilepticus. Epilepsia 1994;35:27-34.

37. Lowenstein DH, Alldredge BK. Status epilepticus at an urban public hospital in the 1980s. Neurology 1993;43:483-488.

38. DeLorenzo RJ, Garnett LK, Towne AR, et al. Comparison of status epilepticus with prolonged seizure episodes lasting from 10 to 29 minutes. Epilepsia 1999;40:164-169.

39. Waterhouse EJ, Garnett LK, Towne AR, et al. Prospective populationbased study of intermittent and continuous convulsive status epilepticus in Richmond, Virginia. Epilepsia 1999;40:752-758.

40. Cascino GD, Hesdorffer D, Logroscino G, Hauser WA. Morbidity of nonfebrile status epilepticus in Rochester, Minnesota, 19651984. Epilepsia 1998;39:829-832.

41. Hesdorffer DC, Logroscino G, Cascino G, Annegers JF, Hauser WA. Risk of unprovoked seizure after acute symptomatic seizure: effect of status epilepticus. Ann Neurol 1998;44: 908-912.

42. Hauser WA, Rich SS, Annegers JF, Anderson VE. Seizure recurrence after a 1st unprovoked seizure: an extended follow-up. Neurology 1990;40:1163-1170.

43. Hauser WA, Anderson VE, Loewenson RB, McRoberts SM. Seizure recurrence after a first unprovoked seizure. $N$ Engl J Med 1982;307:522-528.

44. Alldredge BK, Wall DB, Ferriero DM. Effect of prehospital treatment on the outcome of status epilepticus in children. Pediatr Neurol 1995;12:213-216. 
45. Martin PJ, Millac PA. Status epilepticus: management and outcome of 107 episodes. Seizure 1994;3:107-113.

46. Lowenstein DH, Alldredge BK. Current concepts: status epilepticus. N Engl J Med 1998;338:970-976.

47. Shaner DM, McCurdy SA, Herring MO, Gabor AJ. Treatment of status epilepticus: a prospective comparison of diazepam and phenytoin versus phenobarbitone and optional phenytoin. Neurology 1998;38:202-207.

48. Leppik IE, Derivan AT, Homan RW, et al. Double-blind study of lorazepam and diazepam in status epilepticus. JAMA 1983;249:1452-1454.

49. Walker JE, Homan RW, Vasko MR, et al. Lorazepam in status epilepticus. Ann Neurol 1979;6:207-213.

50. Chiulli DA, Terndup TE, Kanter RK. The influence of diazepam or lorazepam on the frequency of endotracheal intubation in childhood status epilepticus. J Emerg Med 1991;9:13-17.

51. Greenblatt DJ, Divoll M. Diazepam versus lorazepam: relationship of drug distribution to duration of clinical action. Adv Neurol 1983;34:487-491.

52. Sorel L, Mechler L, Harmant J. Comparative trial of intravenous lorazepam and clonazepam in status epilepticus. Clin Ther 1981;4:326-336.

53. Rey E, Treluyer JM, Pons G. Pharmacokinetic optimization of benzodiazepine therapy for acute seizures. Focus on delivery routes. Clin Pharmacokinet 1999;36:409-424.

54. Raines A, Henderson TR, Swinyard EA, Dretchen KL. Comparison of midazolam and diazepam by the intramuscular route for the control of seizures in a mouse model of status epilepticus. Epilepsia 1990;31:313-317.

55. Towne AR, DeLorenzo RJ. Use of intramuscular midazolam for status epilepticus. J Emerg Med 1999;17:323-328.

56. Uthman BM, Wilder BJ, Ramsay RE. Intramuscular use of fosphenytoin: an overview. Neurology 1996;46:S24S-28.

57. Delgado-Escueta AV, Enrile-Bacsal F. Combination therapy for status epilepticus: intravenous diazepam and phenytoin. Adv Neurol 1983;34:477-485

58. Osorio I, Reed RC. Treatment of refractory generalized tonic-clonic status epilepticus with pentobarbital anesthesia after high-dose phenytoin. Epilepsia 1989;30:464-471.

59. Bleck TP. Management approaches to prolonged seizures and status epilepticus. Epilepsia 1999;40:S59-63; discussion S64-S66.

60. Walton NY, Uthman BM, Yafi KE, Kim JM, Treiman DM. Phenytoin penetration into brain after administration of phenytoin or fosphenytoin. Epilepsia 1999;40:153-156.

61. O'Brien TJ, Cascino GD, So EL, Hanna DR. Incidence and clinical consequence of the purple glove syndrome in patients receiving intravenous phenytoin. Neurology 1998;51:1034-1039.

62. Cranford RE, Leppik IE, Patrick B, Anderson CB, Kostick B. Intravenous phenytoin: clinical and pharmacokinetic aspects. Neurology 1978;28:874-880.

63. Donovan PJ, Cline D. Phenytoin administration by constant intravenous infusion: selective rates of administration. Ann Emerg Med 1991;20:139-142.

64. Bertz RJ, Howrie DL. Diazepam by continuous intravenous infusion for status epilepticus in anticonvulsant hypersensitivity syndrome. Ann Pharmacother 1993;27:298-301.

65. Walton NY, Treiman DM. Valproic acid treatment of experimental status epilepticus. Epilepsy Res 1992;12:199-205.

66. Bolanos AR, Sarkisian M, Yang Y, et al. Comparison of valproate and phenobarbital treatment after status epilepticus in rats. Neurology 1998;51:41-48.

67. Venkataraman V, Wheless JW. Safety of rapid intravenous infusion of valproate loading doses in epilepsy patients. Epilepsy Res 1999;35:147-153.

68. Limdi N, Faught RE. The safety of rapid valproic acid infusion. Epilepsia 2000;41:1342-1345.

69. Uberall MA, Trollman R, Wunsiedler U, Wenzel D. Intravenous valproate in pediatric epilepsy patients with refractory status epilepticus. Neurology 2000;54:2188-2199.

70. The Collaborative Eclampsia Trial Group. Which anticonvulsant for women with eclampsia? Evidence from the Collaborative Eclampsia Trial. Lancet 1995;345:1455-1463.
71. Link MJ, Anderson RE, Meyer FB. Effects of magnesium sulfate on pentylenetetrazol-induced status epilepticus. Epilepsia 1991;32:543-549.

72. Krauss GL, Kaplan P, Fisher RS. Parenteral magnesium sulfate fails to control electroshock and pentylenetetrazol seizures in mice. Epilepsy Res 1989;4:201-206.

73. Karceski S, Morrell M, Carpenter D. The expert consensus guideline series-treatment of epilepsy. Epilepsy and Behavior 2001;2:(Suppl) A1-A50.

74. Herkes GK, Wszolek ZK, Westmoreland BF, Klass DW. Effects of midazolam on electroencephalograms of seriously ill patients. Mayo Clin Proc 1992;67:334-338.

75. Igatua J, Silver P, Maytal J, Sagy M. Midazolam coma for refractory status epilepticus in children. Crit Care Med 1999;27:1982-1985.

76. Parent JM, Lowenstein DH. Treatment of refractory generalized status epilepticus with continuous infusion of midazolam. Neurology 1994;44:1837-1840.

77. Kumar A, Bleck T. Intravenous midazolam for the treatment of refractory status epilepticus. Crit Care Med 1992;20:438-488.

78. Fountain NB, Adams RE. Midazolam treatment of acute and refractory status epilepticus. Clin Neuropharmacol 1999;22:261-267.

79. Claassen J, Hirsch LJ, Emerson RG, et al. Continuous EEG monitoring and midazolam infusion for refractory nonconvulsive status epilepticus. Neurology 2001;57:1036-1042.

80. Brown LA, Levin GM. Role of propofol in refractory status epilepticus. Ann Pharmacother 1998;32:1053-1059.

81. Stecker MM, Kramer TH, Raps EC, et al. Treatment of refractory status epilepticus with propofol: clinical and pharmacokinetic findings. Epilepsia 1998;39:18-26.

82. Prasad A, Worrall BB, Bertram EH, Bleck TP. Propofol and midazolam in the treatment of refractory status epilepticus. Epilepsia 2001;42:380-386.

83. Sneyd JR. Excitatory events associated with propofol anaesthesia: a review. J R Soc Med 1992;85:288-291.

84. Orser B. Propofol-induced neuroexcitation and receptor desensitization. Can J Anaesth 1994;41:366-371.

85. Finley GA, MacManus B, Sampson SE, Fernandez CV, Retallick R. Delayed seizures following sedation with propofol. Can J Anaesth 1993;40:863-865.

86. Bevan JC. Propofol-related convulsions. Can J Anaesth 1993;40:805-809.

87. Hewitt PB, Chu DL, Polkey CE, Binnie CD. Effect of propofol on the electrocorticogram in epileptic patients undergoing cortical resection. Br J Anaesth 1999;82:199-202.

88. Cremer OL, Moons KG, Bouman EA, et al. Long-term propofol infusion and cardiac failure in adult head-injured patients. Lancet 2001; 357:117-118.

89. Crawford TO, Mitchell WG, Fishman LS, Snodgrass SR. Very-highdose phenobarbital for refractory status epilepticus in children. Neurology 1988;38:1035-1040.

90. Lowenstein DH, Aminoff MJ, Simon RP. Barbiturate anesthesia in the treatment of status epilepticus: clinical experience with 14 patients. Neurology 1988;38:395-400.

91. Yaffe K, Lowenstein DH. Prognostic factors of pentobarbital therapy for refractory generalized status epilepticus. Neurology 1993;43:895-900.

92. Young GB, Blume WT, Bolton CF, et al. Anesthetic barbiturates in refractory status epilepticus. Can J Neurol Sci 1998;7:291-292.

93. Brown A, Horton J. Status epilepticus treated by intravenous infusions of thiopentone sodium. Br Med J 1967;1:27-28.

94. Roesch C, Haselby KA, Paradise RR, et al. Comparison of cardiovascular effects of thiopental and pentobarbital at equivalent levels of CNS depression. Anesth Analg 1983; 62:749-753.

95. Moudgill GC. Update on anaesthesia and the immune response. Can Anaesth Soc J 1986; 33:S54-S60.

96. Kinoshita H, Nakagawa E, Iwasaki Y, Hanaoka S, Sugai K. Pentobarbital therapy for status epilepticus in children: timing of tapering. Pediatr Neurol 1995;13:164-168.

97. Delgado-Escueta AV, Wasterlain C, Treiman DM, Porter RJ. Status epilepticus: summary. Adv Neurol 1983;34:537-541.

98. Delgado-Escueta AV, Wasterlain C, Treiman DM, Porter RJ. Management of status epilepticus. N Eng J Med 1982;306:1337-1340. 
99. Modica PA, Tempelhoff R, White PF. Pro- and anticonvulsant effects of anesthetics (part 1). Anesth Analg 1990;70:303-315.

100.Kofke WA, Towfighi J, O'Connell BK, Derr J, Hawkins RA. Neuropathological effects of anesthetics used to stop status epilepticus in rats. Anesthesiol Rev 1987;15:27-28.

101.Kofke WA, Towfighi J, Garman RH, et al. Effects of anesthetics on neuropathological sequelae of status epilepticus in rats. Anesth Analg 1993;77:330-337.

102.Murao K, Shingu K, Tsushima K, et al. The anticonvulsant effects of volatile anesthetics on penicillin-induced status epilepticus in cats. Anesth Analg 2000;90:142-147.

103. Kofke WA, Snider MT, Young RSK, Ramer JC. Prolonged low flow isoflurane anesthesia for status epilepticus. Anesthesiology 1985;62:653-656.

104.Kofke WA, Young RSK, Davis P, et al. Isoflurane for refractory status epilepticus: a clinical series. Anesthesiology 1989;71:653-659.

105.Ropper AH, Kofke WA, Bromfield EB, Kennedy SK. Comparison of isoflurane, halothane and nitrous oxide in status epilepticus (letter). Ann Neurol 1986;19:98-99.

106.Iijima T, Nakamura Z, Iwao Y, Sankawa H. The epileptogenic properties of the volatile anesthetics sevoflurane and isoflurane in patients with epilepsy. Anesth Analg 2000;91: 989-995.

107. Sato K, Shamoto H, Kato M. Effect of sevoflurane on electrocorticogram in normal brain. J Neurosurg Anesthesiol 2002; $14: 63-65$.

108.Walker IA, Slovis CM. Lidocaine in the treatment of status epilepticus. Acad Emerg Med 1997;4:918-922.

109.DeToledo JC. Lidocaine and seizures. Ther Drug Monit 2000;22:320-322.

110.Pascual J, Ciudad J, Berciano J. Role of lidocaine in managing status epilepticus. J Neurol Neurosurg Psychiatry 1992;55: 4951.

111. Sheth RD, Gidal BE. Refractory status epilepticus: response to ketamine. Neurology 1998;51:1765-1766. 